\title{
The Treatment of Type 2 Diabetes
}

Andreas F. H. Pfeiffer, Harald H. Klein

\section{SUMMARY}

Background: $5 \%$ to $8 \%$ of adults have type 2 diabetes, a disease that is usually asymptomatic at first. The goals of management are timely diagnosis and the prevention of complications.

Methods: Selective review of the literature, including guidelines from Germany and abroad.

Results: High caloric intake and lack of exercise are the main contributing causes of type 2 diabetes and the principal targets of intervention. If lifestyle changes do not yield adequate improvement, then drug treatment should be initiated (or intensified) and managed on the basis of the $\mathrm{HbA1c}$ fraction. Guidelines recommend an $\mathrm{HbA1c}$ target range of $6.5 \%$ to $7.5 \%$; the individual target value should be chosen in consideration of patient-specific factors and established in collaboration with the patient. Metformin is recommended for initial drug treatment. If metformin is contraindicated, poorly tolerated, or inadequately effective, many therapeutic alternatives and supplements are available. Clinical trials have shown that sulfonylureas and insulin are beneficial with respect to patient-relevant endpoints, but comparable data from clinical trials are not yet available for any other antidiabetic drug (except metformin). For individual patients, other drugs may have advantages such as a lower risk of hypoglycemia, less weight gain, oral administration, and/or applicability in the setting of renal insufficiency. The treatment is individually oriented, depending on the patient's age, disease stage, body weight, comorbidities, work situation, adherence, and personal priorities. Combining more than two antidiabetic drugs is not recommended.

Conclusion: Although there are many treatment options, individualized long-term treatment still presents a challenge in many cases.

\footnotetext{
Cite this as:

Pfeiffer AFH, Klein HH: The treatment of type 2 diabetes. Dtsch Arztebl Int 2014; 111(5): 69-82. D0I: 10.3238/arztebl.2014.0069
}

German Institute of Human Nutrition (DlfE) Potsdam-Rehbrücke, Nuthetal: Prof. Dr. med. Pfeiffer

Department of Endocrinology and Metabolic Diseases, Charité Campus Benjamin Franklin, Charité Universitätsmedizin Berlin: Prof. Dr. med. Pfeiffer Medical Clinic I (General Internal Medicine, Endocrinology and Diabetology, Gastroenterology and Hepatology), Berufsgenossenschaftliches Universitätsklinikum Bergmannsheil, Klinikum der Ruhr-Universität Bochum:

Prof. Dr. med. Klein

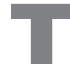
ype 2 diabetes is a metabolic disorder characterized by chronically elevated blood glucose levels. It typically results from caloric intake in excess of energy consumption, combined with inadequate insulin secretion because of dysfunction of the insulin-secreting pancreatic beta cells. Caloric excess triggers an adaptation of metabolism that has been conserved throughout evolution (as does a caloric deficit due to dietary restriction). Caloric excess induces an inhibition of the further uptake of energybearing substrate into muscle, adipose tissue, and the liver, giving rise to the clinical picture of insulin resistance (1). This is associated with multiple further disturbances of energy metabolism, because insulin is the primary regulatory hormone, not only of glucose metabolism, but of fat and protein metabolism as well (2).

Obesity, especially when fatty tissue is mainly abdominally distributed and when combined with physical inactivity, is often associated with high triglyceride levels and low HDL cholesterol levels, impaired glucose tolerance and/or a high fasting blood glucose concentration, hypertension, high fibrinogen levels, subclinical inflammation, microalbuminuria, non-alcoholic fatty liver disease, and hyperuricemia (3).

Insulin resistance raises the body's demand for insulin and causes hyperglycemia unless the pancreatic beta cells can secrete enough insulin to compensate for it. The adequacy or inadequacy of the beta-cell response is largely genetically and epigenetically determined. Most of the over 50 "diabetes genes" identified to date affect beta-cell function and regeneration (4).

The prevalence of diabetes mellitus in Germany is now $5 \%$ to $8 \%$, and increasing (5). As an individual's blood glucose concentration rises, so does the risk of microvascular complications affecting the eyes, nervous system, and kidneys (1). Diabetes is, there-

\section{Definition}

Type 2 diabetes results from impaired insulin sensitivity combined with inadequate insulin secretion. 
BOX 1

\section{Lifestyle modification and dietary therapy for type 2 diabetes}

- Individualized patient training and counseling improve metabolic control and should be initiated as soon as type 2 diabetes is diagnosed.

- Having the patient engage in personally suitable physical exercise for at least 30 minutes daily is a basic element of therapeutic lifestyle modification.

- Weight targets should be set individually, and strategies for reaching them should be discussed in relation to the overarching importance of achieving energetic balance.

- Individualized dietary counseling should proceed from the patient's eating habits and preferences and present practical examples of what is to be done.

- The patient should become aware of the effect of carbohydrates on blood glucose levels. Carbohydrates should be eaten mainly in vegetable form; consumption of starchy vegetables (potatoes, rice, corn) should be reduced and fruit can be eaten in moderation. The patient should be able to estimate roughly the amount of carbohydrate consumed.

- Sugar is permitted, in moderation. Dietetic products with fructose are harmful and to be avoided. Sweeteners are permitted and metabolically unproblematic.

- The goal of eating $30 \mathrm{~g} /$ day of dietary fiber should be presented so that it can be practically implemented.

- Information about fats, the saturated and hydrogenated fat content of various foods, and the goal of restricting saturated fats to $7-10 \%$ of energy intake should be presented in a way that can be practically implemented.

- Alcohol is permitted, in moderation (women, up to $15 \mathrm{~g} /$ day; men, up to $30 \mathrm{~g} /$ day).

- The relative amounts of protein (10-25\%), fat (25$40 \%$ ), and carbohydrates (40-55\%) are adjustable individually for each patient.

${ }^{* 1}$ modified from $(3,11, \mathrm{e} 25-\mathrm{e} 27)$ fore, the commonest cause of blindness, renal failure, and lower-limb amputation.

Prospective observational studies have shown that high blood glucose is associated with an increased risk of cardiovascular diseases and cancer $(3,6)$.

\section{Learning objectives}

Readers of this article should be able to:

- establish treatment goals in consideration of individual patient characteristics;

- know the pharmacological properties, advantages, and disadvantages of the available antihyperglycemic drugs and make wellinformed and well-reasoned individual therapeutic decisions;

- know the basic principles of the use of insulin(s) and its (their) combination with other drugs that lower the blood glucose concentration.

\section{Editorial comment}

This text is patterned on the recommendations of the German National Disease Management Guideline on the Treatment of Type 2 Diabetes (Nationale Versorgungsleitlinie Therapie des Typ-2-Diabetes, Version 3; www.versorgungsleitlinien.de/themen/diabetes $2 / \mathrm{dm} 2$ ther apie/pdf/nvl-t2d-therapie-kurz-3.pdf). The guideline contains somewhat divergent algorithms for pharmacotherapy, which are based, on the one hand, on the recommendations of the German Society of General Practice and Family Medicine (Deutsche Gesellschaft für Allgemeinmedizin und Familienmedizin, DEGAM) and the Drug Commission of the German Medical Association (Arzneimittelkommission der Ärzteschaft, $\operatorname{AkdÄ}$ ), and, on the other hand, on those of the German Diabetes Society (Deutsche Diabetes Gesellschaft, DDG) and the German Society of Internal Medicine (Deutsche Gesellschaft für Innere Medizin, DGIM) (Figure). In this review, the authors generally refer to the algorithm of the DDG unless otherwise noted.

\section{Non-pharmacological treatment}

Caloric restriction and physical exercise, even in the short term, activate cellular mechanisms that protect the organism by:

- improving mitochondrial function,

- lessening the generation of radicals,

- inhibiting proliferation, and

- improving the efficacy of insulin (7).

\section{Prevalence}

The prevalence of diabetes mellitus in Germany is now $5-8 \%$, and increasing.

\section{Non-pharmacological treatment}

Caloric restriction and physical exercise, even in the short term, activate cellular mechanisms that protect the organism. 
Weight loss improves the patient's metabolic state, with proportional decreases in blood pressure, blood glucose and lipid concentrations, and hepatic fat content (8). These improvements are the aim of lifestyle therapy. They have been documented in large-scale, randomized, prospective trials, such as the UK Prospective Diabetes Study (UKPDS), in which initial training over a three-month period resulted in a $1 \%$ drop of the HbA1c fraction in 3867 patients (9). In the Look AHEAD (Action for Health in Diabetes) trial, intensive lifestyle modification was tested against conventional diabetes support and education in a group of 5000 diabetic patients over a period of four years; intensive training brought about a mean weight loss of $4.5 \mathrm{~kg}$ compared to conventional training $(10,11)$. The extent of weight loss was directly correlated with reductions in the HbAlc fraction (by $0.3-1 \%$ ), triglyceride concentrations, and systolic and diastolic blood pressure, as well as with a rise in the HDL cholesterol level (11). Glucose metabolism was already markedly improved four to seven days after (8) caloric restriction to $600-800 \mathrm{kcal} / \mathrm{day}$; this corresponds to about half of the effect achievable by weight loss over eight weeks (7). Glucose metabolism can be normalized by caloric restriction to 600 $\mathrm{kcal} /$ day for eight weeks (12).

Aside from weight, the main factors influencing metabolism are the composition of the diet and the level of physical activity. It is on these factors that individualized counseling and training must be based (Box 1).

\section{The goals of pharmacotherapy}

The long-term treatment of type 2 diabetes has the following main goals:

- the prevention of microangiopathic complications - retinopathy, nephropathy, neuropathy;

- the prevention of macroangiopathic complications-myocardial infarction, stroke, limb loss;

- restoration of quality of life;

- improvement in accompanying illnesses;

- patient satisfaction and adherence;

- the avoidance of hypoglycemia and weight gain.

There is a scientific consensus that the risk of diabetic complications rises steadily when $\mathrm{HbAlc}$ values are in excess of $6.5 \%(48 \mathrm{mmol} / \mathrm{mol})(13,16)$. Therefore, from 2010/2011 onward, this value has been incorporated as a diagnostic criterion in the

\section{BOX 2}

\section{Treatment goals in type 2 diabetes}

The following treatment goals may need to be adapted depending on the patient's comorbidities, age, and life expectancy.

- Maintenance and restoration of quality of life

- Risk reduction for cardiac, cerebrovascular, and other macroangiopathic complications of diabetes, and for the diabetic foot syndrome

- Avoidance and treatment of microangiopathic complications (blindness, end-stage renal failure, neuropathy)

- Improvement of the patient's competence to deal with the illness

- Satisfaction with treatment

- Explicit statement of treatment goals to promote patient adherence

- Avoidance and treatment of diabetic manifestations through improved metabolic control, with therapeutic targets that should be set individually in mutual agreement with the patient:

- blood pressure: $130-140 / 80-85 \mathrm{~mm} \mathrm{Hg}^{*}$

- total cholesterol: $<180 \mathrm{mg} / \mathrm{dL}(<4.7 \mathrm{mmoL} / \mathrm{L})$

- LDL: $<100 \mathrm{mg} / \mathrm{dL}$ (<2.6 mmol/L), in $\mathrm{CHD}<70 \mathrm{mg} / \mathrm{dL}$ ( $<1.8 \mathrm{mmol} / \mathrm{L})$

- HDL: $\widehat{\sigma}>40 \mathrm{mg} / \mathrm{dL}(>1.1 \mathrm{mmol} / \mathrm{L}) ;$; $>50 \mathrm{mg} / \mathrm{dL}(>1.3 \mathrm{mmol} / \mathrm{L})$

- triglycerides: $<150 \mathrm{mg} / \mathrm{dL}(<1.7 \mathrm{mmol} / \mathrm{L})$

- smoking cessation

- overweight and obese patients (without cardiac insufficiency): weight loss

- physical exercise, ca. $150 \mathrm{~min} /$ week

- fasting blood sugar $100-125 \mathrm{mg} / \mathrm{dL}(5.6-6.9 \mathrm{mmol} / \mathrm{L})$

These target values have been adapted from the original guideline information on the basis of current data and with reference to the guideline of the European Society of Hypertension (e28) and positions taken by the German Diabetes Society and the German Hypertension League (Deutsche Hochdruckliga e. V.). The blood-pressure target values should be in the lower portion of this range.

recommendations of the World Health Organization (WHO) (14), the German Diabetes Society (DDG) (15), and the current German National Disease Management Guideline on the Treatment of Type 2 Diabetes.

The fact that higher blood glucose values are associated with a higher risk of complications does not necessarily imply that patients with type 2 diabetes will benefit clinically from treatment with antihyperglygemic drugs to drive their $\mathrm{HbAlc}$ value below the threshold level for the diagnosis of diabetes. Clinical trials have shown that glycemic control to as near a

\section{The goals of long-term treatment}

- prevention of micro- and macroangiopathic complications

- restoration of quality of life

- improvement in accompanying illnesses

- patient satisfaction with treatment

\section{HbA1c values}

It is recommended that the $\mathrm{HbA1c}$ target should be individually set in the $6.5-7.5 \%$ range. An $\mathrm{HbA1C}$ below $6.5 \%$ is recommended only for patients who can achieve such values without drugs, or with drugs that carry a low risk of severe side effects. 


\section{Individualized HbA1c target values}

- The target value for $\mathrm{HbA} 1 \mathrm{c}$ should be set individually, by mutual agreement with the patient, in the light of: - patient preferences after full medical information

- age and comorbidities

- weighing treatment benefits (lower risk of diabetic complications) against possible harms (e.g., higher risk of hypoglycemic episodes and weight gain)

- type of treatment to be given.

- The $\mathrm{HbA} 1 \mathrm{c}$ value should be in the lower portion of the range $6.5-7.5 \%$ (48-58 $\mathrm{mmol} / \mathrm{mol})$, or perhaps even lower, in these situations:

- recently diagnosed diabetes, only moderately elevated $\mathrm{HbA} 1 \mathrm{c}$ values till now, no cardiovascular abnormality, and/or

- target achievable without major difficulties or side effects (hypoglycemic episodes, weight gain).

- The HbA1c value should be in the upper portion of the range, or perhaps even higher, in these situations:

- longstanding poorly controlled diabetes and/or already existing cardiovascular disease, poor glycemic control, and elevated risk of hypoglycemia, or

- comorbidities, life expectancy, and/or accompanying circumstances that do not justify the difficulty and risk associated with a low $\mathrm{HbA} 1 \mathrm{c}$ target in relation to the expected benefit (complication avoidance).

normoglycemic state as possible helps prevent microangiopathic complications (retinopathy and nephropathy) (16-18); nonetheless, in other studies, the two- to fivefold elevation of cardiovascular mortality among persons with diabetes (19) was not lowered by intensive pharmacotherapy to keep the blood glucose concentration in a the near-normal range (the mean achieved $\mathrm{HbA} 1 \mathrm{c}$ values were in the range of $6.4 \%$ to $6.9 \%$, corresponding to $46-52 \mathrm{mmol} / \mathrm{mol}$, compared to $7.5 \S$ to $8.5 \%$ [58-69 $\mathrm{mmol} / \mathrm{mol}]$ without intensive glucose control) $(18,20,21)$. Meta-analyses incorporating the findings of these and other trials have led to the conclusion that the evidence favors a reduction of nonfatal myocardial infarction or microvascular endpoints, but not of cardiovascular or overall mortality, or of stroke (22-24). Trials conducted over longer periods with patient-relevant endpoints are now called for (23-26).

A possible reason why tight glycemic control failed to lower cardiovascular mortality in the trials discussed above is that the putative benefit of normalizing the blood glucose concentration may have been canceled out, or even reversed, by other, detrimental effects of the antihyperglycemic treatment regimens used (20). Such effects might include the induction of hypoglycemia, the promotion of weight gain, and other adverse effects of the drugs used in the trials. Subgroup analyses indicate that overzealous normalization of the HbA1c may be detrimental, in particular, when:

- the patient has had poorly-controlled diabetes for many years;

- significant cardiovascular disease is already present;

- the patient has a tendency toward hypoglycemia; or

- the goal of treatment is hard to attain.

Patients do, however, stand to benefit over the long term from glycemic control that is as tight as possible if it is implemented soon after the diagnosis is made; the benefit extends to macrovascular complications as well (26). This underscores the importance of setting the HbA1c target individually.

In view of this complex situation, the American Diabetes Association (ADA) and the European Association for the Study of Diabetes (EASD) (1) concur with the new German National Disease Management Guideline on the Treatment of Type 2 Diabetes (27) in recommending a patient-centered treatment approach based on the patient's living situation, duration of illness, diabetic complications, comorbidities, age, and, above all, personal preferences. It is generally agreed that complications are best avoided if the target range for HBA1c is set at $6.5 \%$ to $7.5 \%$ (48-58 mmol/mol) (27). This roughly corresponds to a fasting blood glucose concentration of $100-125 \mathrm{mg} /$ $\mathrm{dL}(5.6-6.9 \mathrm{mmol} / \mathrm{L})$, and to a postprandial glucose concentration of $140-199 \mathrm{mg} / \mathrm{dL}(7.8-11.0 \mathrm{mmol} / \mathrm{L})$. The goals of treatment should be agreed upon with the patient in a detailed discussion. An HbA1c of $6.5 \%$ or lower is recommended for patients who can achieve such values without drugs, or with low-risk treatment. Conversely, for multimorbid patients who need complex treatment with its attendant risks, the avoidance of adverse drug effects is particularly a high priority,
Patients for whom the HbA1c target should not be set too low

Overzealous normalization of the HbA1c may be detrimental for patients with preexisting cardiovascular disease, and when tight glycemic control is difficult and would be associated with a risk of hypoglycemia.

\section{Antihyperglycemic pharmacotherapy}

A single antihyperglycemic drug (monotherapy) often suffices initially, but a second drug with a different mechanism of action usually needs to be added later on (combination therapy). 
The main properties of antihyperglycemic drugs

\begin{tabular}{|c|c|c|c|c|}
\hline & $\begin{array}{l}\text { Risk of } \\
\text { hypoglycemia / } \\
\text { weight gain }\end{array}$ & $\begin{array}{l}\text { Minimum*1 required GFR } \\
\text { [mL/min] stated in physici- } \\
\text { ans' information, } 9 / 2012\end{array}$ & Special properties & Typical application \\
\hline Metformin & $n *^{* 2} / \mathrm{no}$ & 60 & $\begin{array}{l}\text { gastrointestinal side effects } \\
\text { are common, particularly at } \\
\text { the beginning of treatment: } \\
\text { start at a low dose! }\end{array}$ & $\begin{array}{l}\text { first-line drug for } \\
\text { type } 2 \text { diabetes }\end{array}$ \\
\hline Sulfonylureas & yes/yes & $\begin{array}{l}\text { with dose reduction: } 30 \\
\text { gliquidone, } \\
\text { without dose reduction: } 30\end{array}$ & $\begin{array}{l}\text { the sulfonylureas have been } \\
\text { well established for many } \\
\text { years as effective antihyper- } \\
\text { glycemic drugs }\end{array}$ & $\begin{array}{l}\text { inexpensive combination } \\
\text { partner for metformin; } \\
\text { inexpensive alternative to } \\
\text { metformin if the latter is } \\
\text { contraindicated or poorly } \\
\text { tolerated }\end{array}$ \\
\hline Glinides & yes/yes & $\begin{array}{l}\text { repaglinide*7: } \\
\text { renal insufficiency } \\
\text { is not a contraindication, } \\
\text { dose adjustment } \\
\text { recommended }\end{array}$ & $\begin{array}{l}\text { more flexible than sulfonyl- } \\
\text { ureas because of their faster } \\
\text { onset and shorter duration of } \\
\text { action }\end{array}$ & $\begin{array}{l}\text { superior to sulfonylureas if } \\
\text { meals are taken irregularly or } \\
\text { unreliably, as well as for } \\
\text { patients with renal insuffi- } \\
\text { ciency }\end{array}$ \\
\hline $\begin{array}{l}\text { DPP-4 } \\
\text { inhibitors }\end{array}$ & $\mathrm{no}^{* 2} / \mathrm{no}$ & $\begin{array}{l}\text { sitagliptin, vildagliptin: } 50 \text {, } \\
\text { dose adjustment up to ESRF } \\
\text { saxagliptin: } 60 \text {, with dose } \\
\text { adjustment as low as } 15 \text {, not } \\
\text { recommended in ESRF } \\
\text { linagliptin*6: no dose } \\
\text { adjustment required, even in } \\
\text { severe renal insufficiency }\end{array}$ & $\begin{array}{l}\text { advantage compared to } \\
\text { GLP-1 receptor agonists: } \\
\text { oral administration }\end{array}$ & $\begin{array}{l}\text { inadequate glycemic control } \\
\text { with metformin alone, } \\
\text { elevated risk of hypogly- } \\
\text { cemia, overweight }\end{array}$ \\
\hline $\begin{array}{l}\text { SGLT-2 } \\
\text { inhibitors }\end{array}$ & $\mathrm{no}^{* 2} / \mathrm{no}$ & 60 (dapagliflozine) & $\begin{array}{l}\text { weight loss; } \\
\text { elevated risk } \\
\text { of genital infections }\end{array}$ & $\begin{array}{l}\text { inadequate glycemic control } \\
\text { with metformin alone, } \\
\text { elevated risk of hypogly- } \\
\text { cemia, overweight }\end{array}$ \\
\hline $\begin{array}{l}\text { GLP-1 } \\
\text { receptor } \\
\text { agonists }\end{array}$ & $\mathrm{no}^{* 2} / \mathrm{no}$ & $\begin{array}{l}\text { liraglutide: } 60 \\
\text { exenatide, lixisenatide: } 50 \text {, } \\
\text { cautiously and with dose } \\
\text { adjustment as low as } 30^{* 5}\end{array}$ & $\begin{array}{l}\text { given subcutaneously; more } \\
\text { effective than the DPP-4 } \\
\text { inhibitors, with the added } \\
\text { advantage of weight loss }\end{array}$ & $\begin{array}{l}\text { inadequate glycemic control } \\
\text { with metformin alone, } \\
\text { elevated risk of hypogly- } \\
\text { cemia, overweight }\end{array}$ \\
\hline Acarbose & $\mathrm{no}^{* 2} / \mathrm{no}$ & 25 & $\begin{array}{l}\text { gastrointestinal side effects } \\
\text { are common (flatulence) }\end{array}$ & $\begin{array}{l}\text { early type } 2 \text { diabetes, or else } \\
\text { as combination partner }\end{array}$ \\
\hline Pioglitazone $^{* 3}$ & no $^{* 2} /$ yes $^{* 4}$ & 4 & $\begin{array}{l}\text { risk of fluid retention and } \\
\text { cardiac insufficiency; } \\
\text { increased propensity to bone } \\
\text { fractures; possibly increased } \\
\text { risk of bladder cancer }\end{array}$ & $\begin{array}{l}\text { combination partner for } \\
\text { patients at elevated risk of } \\
\text { hypoglycemia and those with } \\
\text { severe renal insufficiency }\end{array}$ \\
\hline Insulin & yes/yes & no restriction & & $\begin{array}{l}\text { necessary in advanced } \\
\text { stages of the disease; may } \\
\text { be reasonably combined with } \\
\text { metformin }\end{array}$ \\
\hline
\end{tabular}

GFR, glomerular filtration rate; DPP-4, dipeptidylpeptidase-4; GLP-1, glucagon-like-peptide 1; ESRF, end-stage renal failure.

${ }^{* 1}$ Patients with inadequate metabolic control under oral antidiabetic treatment, a tendency to hypoglycemic episodes, or worsening of their general condition should be treated with some type of insulin therapy regardless of whether their renal clearance is normal or impaired. This holds especially for patients with highly variable renal function (www.diabetes.versorgungsleitlinien.de [27]).

*2 Statement not valid when this drug is used in combination with a drug that can cause hypoglycemia.

${ }^{*}$ Pioglitazone was removed from the list of reimbursable drugs in the German statutory health insurance system in March 2011.

${ }^{* 4}$ Weight gain affects primarily subcutaneous fat rather than the metabolically more harmful visceral fat.

${ }^{*}$ Exenatide: not applicable for the long-acting formulation of the drug.

${ }^{*}$ Not available in Germany.

${ }^{7}$ Nateglinide is approved only for use in combination with metformin and therefore cannot be given to patients with renal insufficiency.

\section{Adequate insulin when the blood glucose is low}

DPP-4 inhibitors, incretin mimetics, metformin, acarbose, pioglitazone, and SGLT-2 inhibitors decrease insulin secretion when the glucose concentration is low and therefore carry only a low risk of hypoglycemia.

\section{Glucose-independent rises of insulin concentration}

If a drug raises the insulin concentration independently of the blood glucose concentration, there is a risk of temporarily or permanently excessive insulin levels leading to weight gain and hypoglycemia. 


\section{Comments on the Figure "Treatment Algorithm for Type 2 Diabetes"}

The Figure and the accompanying text were taken from the long version of the German National Disease Management Guideline on the Treatment of Type 2 Diabetes (27), with kind permission. The content is largely unchanged, with slight editorial alterations and cuts.

Because of differing interpretations of the scientific evidence, somewhat divergent recommendations for treatment were issued by the German Society of General Practice and Family Medicine (Deutsche Gesellschaft für Allgemeinmedizin und Familienmedizin, DEGAM) and the Drug Commission of the German Medical Association (Arzneimittelkommission der Ärzteschaft, AkdÄ) on the one hand, and by the German Diabetes Society (Deutsche Diabetes Gesellschaft, DDG) and the German Society of Internal Medicine (Deutsche Gesellschaft für Innere Medizin, DGIM) on the other. These differences are reflected in the treatment algorithm.

\section{- AkdÄ/DEGAM}

${ }^{* 1}$ Lifestyle modification (non-pharmacologic measures) are important, but often insufficient. If it is clear in an individual case that lifestyle modification alone will not suffice (poor adherence, severe hyperglycemia, multimorbidity), these measures can be combined with metformin treatment from the outset.

${ }^{*} \mathrm{HbA} 1 \mathrm{c}$ target range: $6.5-7.5 \%$. HbA1c target values near $6.5 \%$ should only be attempted with the aid of lifestyle changes and/or metformin treatment.

${ }^{*}$ For the therapeutic role of each individual drug or group of drugs, cf. background information, Chapter H 6 (27).

${ }^{*}$ Drugs for which no clinical trials with diabetes-relevant endpoints are available.

${ }^{*}$ It is presumed that not all sulfonylureas are equally effective (27).

${ }^{* 6}$ If the therapeutic effect is still inadequate after treatment step 2, the need for lifestyle modification should be discussed again with the patient. If a second antihyperglycemic drug is still needed, then the adding-on of insulin is recommended as the preferred next step. Combinations of two oral antidiabetics should only be given if the patient, after being informed of the possible harm that may result, wants to lower the $\mathrm{HbA} 1 \mathrm{c}$ level but still does not feel ready to accept insulin treatment. ${ }^{* 7}$ Combinations of metformin with a sulfonylurea (glibenclamide) may increase cardiovascular mortality (27).

${ }^{* 8}$ The reason why GLP-1 receptor agonists and SGLT-2 inhibitors are not mentioned here is didscussed in (27).

A combination of metformin with a DPP-4 inhibitor has been mentioned as a possible third option. Drugs of the latter class do not cause hypoglycemia by themselves, nor do they cause weight gain or weight loss or any increase in cardiovascular endpoints. Concerns have been raised, hosever, by clinical trials of DPP-4 inhibitors in which pancreatitis and warning signs for pancreatic tumors were found to be more common. In diabetics over age 70 , HbA1c levels above $8 \%$ can be tolerated as long as no diabetes-associated symptoms arise. The risk of hypoglycemic episodes is lower in this situation, and, therefore, a major argument against combining metformin with insulin becomes inapplicable. No clinical trials with diabetes-relevant endpoints are available for triple combinations of oral antidiabetic drugs, and the safety of such combinations is limited by the increased risk of unwanted drug interactions. For these reasons, triple combinations are not recommended.

\section{- DDG/DGIM}

${ }^{* 1}$ Lifestyle modification (non-pharmacologic measures) is the foundation of treatment in all stages of diabetes but is often insufficient in itself. Lifestyle changes can be combined with metformin from the very outset of treatment in patients for whom lifestyle changes alone are not expected to suffice (because of poor adherence, severity of disease, or multimorbidity).

${ }^{*} \mathrm{HbA} 1 \mathrm{c}$ target range: $6.5-7.5 \%$. HbA1c target values near $6.5 \%$ should only be attempted if:

- hypoglycemic episodes (and severe ones in particular) can be practically excluded

- the benefit of treatment is not accompanied by substantial weight gain

- combinations of oral antidiabetic drugs that cause hypoglycemia are avoided

- type 2 diabetes was recently diagnosed, and there are no clinically relevant comorbidities.

${ }^{*}$ For the therapeutic role of each individual drug or group of drugs, cf. the chapter on pharmacotherapy (27).

${ }^{*}$ Combinations of metformin with a sulfonylurea (glibenclamide) may increase cardiovascular mortality. Many retrospective analyses of sulfonylurea treatment with and without metformin have revealed significant increases of cardiovascular complications and mortality.

${ }^{*}$ It is presumed that not all sulfonylureas are equally effective. Sulfonylureas also often have side effects that make the individualized goals of treatment harder to achieve.

${ }^{* 6}$ These two drugs are rarely prescribed. Pioglitazone is no longer reimbursable by German statutory health insurance.

${ }^{* 7}$ No clinical trials with diabetes-relevant endpoints are available for triple combinations of oral antidiabetic drugs. The safety of, and compliance with, such combinations are limited by the increased risk of unwanted drug interactions. Triple combinations may nonetheless be desirable and reasonable, particularly when none of the drugs used causes hypoglycemia.

${ }^{* 8}$ See the long version (27) for a critical assessment of the evidence regarding treatment with sulfonylureas. 


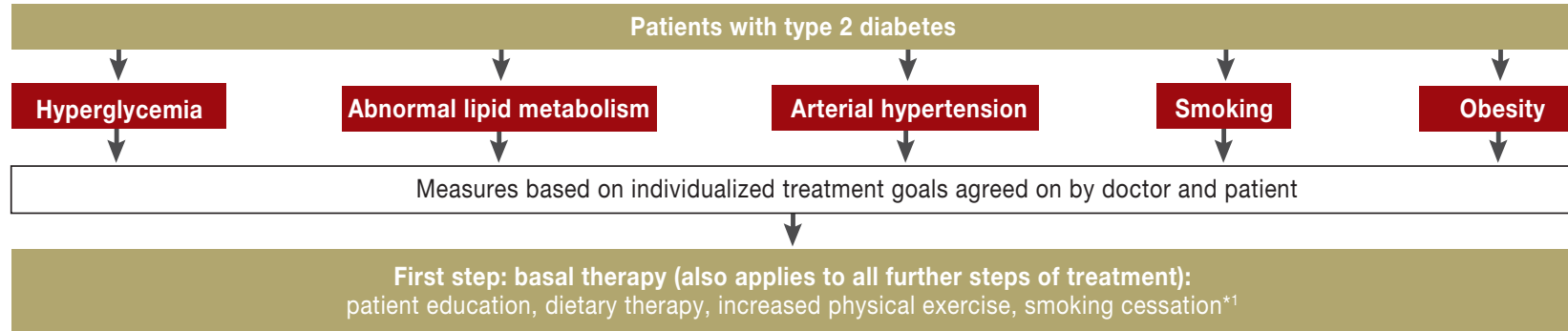
patient education, dietary therapy, increased physical exercise, smoking cessation*

\section{HbA1c target range: $6.5 \%$ to $7.5 \%$}

Individualized $\mathrm{HbA1c}$ target $^{\star 2}$ not achieved after 3 to 6 months of treatment

\section{Second step: basal therapy plus drug monotherapy}

Monotherapy according to DEGAM/AkdÄ, if metformin is not tolerated:

Treatments with demonstrated efficacy in clinical endpoint trials ${ }^{* 3}$

- human insulin: ${ }^{* 4}$ conventional insulin therapy (CT) or preprandial short-acting

insulin (SIT)

- glibenclamide (sulfonylurea)*4,5

Treatments whose efficacy has not been demonstrated in endpoint trials

(in alphabetical order) ${ }^{* 3}$

- DPP-4 inhibitors

- glucosidase inhibitors

- other sulfonylureas, glinides

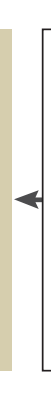

$\downarrow$

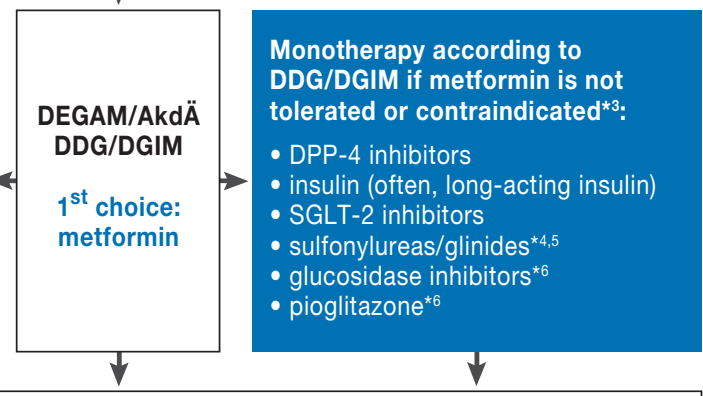

Individualized $\mathrm{HbA} 1 \mathrm{c}$ target $^{\star 2}$ not achieved after 3 to 6 months of treatment

\begin{tabular}{|c|c|c|}
\hline \multicolumn{3}{|c|}{$\downarrow$} \\
\hline \multicolumn{3}{|c|}{ Third step: insulin alone or as part of a two-drug combination } \\
\hline \multicolumn{2}{|c|}{$\downarrow$} & $\downarrow$ \\
\hline \multicolumn{2}{|c|}{$\begin{array}{l}\text { Insulin alone or in a two-drug combination according to DEGAM/Akd } \ddot{A}^{* 6} \\
\text { No recommendation is given for this step of treatment; rather, three options are listed, } \\
\text { and the advantages and disadvantages of each are stated. }\end{array}$} & $\begin{array}{l}\text { Two-drug combination according to } \\
\text { DDG/DGIM: } \\
\text { (drugs listed in alphabetical order):*7 }\end{array}$ \\
\hline \multicolumn{2}{|c|}{$\begin{array}{l}\text { - metformin and insulin } \\
\text { - metfontage: high-quality endpoint trials; disadvantage: hypoglycemia, weight gain } \\
\text { advantage: oral admininistration; disadvantage: elevated cardiovascular mortality in } \\
\text { low-quality studies, hypoglycemia, weight gain } \\
\text { - metformin and DPP-4 inhibitor } \\
\text { advantage: oral administration, hypoglycemia unlikely, no weight gain or loss; } \\
\text { disadvantage: no data on clinical endpoints, studies indicate possibly elevated risk of } \\
\text { pancreatitis and pancreatic tumors } \\
\text { In view of the advantages and disadvangages of each of these treatment schemes, } \\
\text { the choice among them must be made individually for each patient }{ }^{\star 8}\end{array}$} & $\begin{array}{l}\text { - DPP-4 inhibitors } \\
\text { - GLP-1 receptor agonists } \\
\text { - glucosidase inhibitors } \\
\text { - insulin (often, long-acting insulin) } \\
\text { - SGLT-2 inhibitors } \\
\text { - sulfonylureas/glinides } * 4,5,8 \\
\text { - pioglitazone }{ }^{* 6}\end{array}$ \\
\hline \multicolumn{3}{|c|}{ Individualized $\mathrm{HbA} 1 \mathrm{c}$ target ${ }^{\star 2}$ not achieved after 3 to 6 months of treatment } \\
\hline \multicolumn{3}{|c|}{$\downarrow$} \\
\hline \multicolumn{3}{|c|}{ Fourth step: (re-)intensified types of insulin and combination therapy } \\
\hline 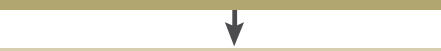 & & $\downarrow$ \\
\hline $\begin{array}{l}\text { Intensive insulin and combination } \\
\text { therapy according to DEGAM/AkdÄ: } \\
\text { - insulin } \\
\text { - preprandial short-acting (SIT), or } \\
\text { - conventional (CT), or } \\
\text { - intensified (ICT) }\end{array}$ & \multicolumn{2}{|c|}{$\begin{array}{l}\text { Intensive insulin and combination therapy according to DDG/DGIM: } \\
\text { In addition to an oral antidiabetic drug (esp. metformin, possibly a DPP-4 inhibitor } \\
\text { or SGLT-2 inhibitor) } \\
\text { - long-acting insulin, or } \\
\text { - long-acting insulin and a GLP-1 receptor agonist (check approval status!), or } \\
\text { - preprandial short-acting insulin (SIT), or } \\
\text { - conventional insulin therapy (CT), or } \\
\text { - intensified insulin therapy (ICT, CSII) }\end{array}$} \\
\hline
\end{tabular}

Treatment algorithm for type 2 diabetes (from [27]). For further comment, see Box 4. 
and an $\mathrm{HbA} 1 \mathrm{c}$ target above $7.5 \%$ may be reasonable $(1,27)$.

\section{Classes of antihyperglycemic drugs}

Antihyperglycemic drugs have diverse mechanisms of action (Table).

All except insulin require some degree of residual insulin secretion to work and are less than totally effective in themselves for the achievement of glycemic control. A single antihyperglycemic drug (monotherapy) often suffices initially, but a second drug with a different mechanism of action usually needs to be added later on (combination therapy). Owing to a lack of clinical trials involving triple combinations, the current recommendations restrict combination therapy to two drugs (27); in advanced diabetes, insulin is needed, either as the partner drug in combination therapy, or else as monotherapy. The choice of a suitable drug(s) for the individual patient is based on the patient's stage of disease, age, body weight, and comorbidities, as well as on the risk associated with a hypoglycemic episode at work, patient adherence, and personal preferences.

Sulfonylureas, glinides, DPP-4 inhibitors, incretin mimetics, and, of course, insulin itself lower the blood glucose concentration by elevating the concentration of insulin. If the rise in insulin concentration occurs independently of the glucose concentration, i.e., even if the glucose concentration is low (sulfonylureas, glinides, insulin), then there is a risk of hypoglycemia. DPP-4 inhibitors and incretin mimetics do not carry this risk, as these drugs increase insulin secretion only when the glucose concentration is high and decrease it when the glucose concentration is low. This attractive feature is shared by a variety of drugs with other mechanisms of action, including metformin, acarbose, pioglitazone, and the SGLT-2 inhibitors (which were approved in late 2012). These drugs do not carry a risk of hypoglycemia unless they are combined with one of the drugs mentioned above that do carry such a risk, or in special situations (Addison's disease, cachexia).

Moreover, drugs that raise the insulin level in a glucose-independent manner can also cause weight gain as a result of temporarily or persistently excessive insulin concentrations ("over-insulinization") (Table). In the long run, weight gain can worsen the course of the disease (28-31).

\section{Metformin as the drug of first choice}

The key advantages of metformin are the documented reduction of mortality, the absence of a risk of hypoglycemia, an anorexic effect that promotes weight loss, and beneficial effects on lipid concentrations.

\section{Metformin as a first-line drug}

Lifestyle interventions and metformin constitute the initial treatment recommended in nearly all guidelines (Figure) $(1,19,30)$. Well-motivated patients with an only mild-to-moderate elevation of the $\mathrm{HbA1c}$ level can be treated initially in a three-month phase without any drug at all, but metformin can also be given at the outset of treatment.

The key advantages of metformin are the reduction of mortality, as documented in the UKPDS (32); the absence of a risk of hypoglycemia; an anorexic effect that promotes weight loss; and beneficial effects on lipid concentrations. Metformin is particularly suitable for obese, insulin-resistant patients, but it is effective for thin patients as well. Recent observational studies have yielded evidence that metformin may lower cancer-related mortality in persons with diabetes $(33,34)$. The main contraindication to metformin is a glomerular filtration rate (GFR) below $60 \mathrm{~mL} / \mathrm{min}$ (35), because of the still inadequate scientific data on the risk of lactic acidosis in this situation (36-38). Further contraindications include marked hypoxic comorbidities, severe liver disease, and states that increase the risk of metabolic acidosis, e.g., fasting. Metformin often has gastrointestinal side effects, mainly at the start of treatment (31). Metformin should, therefore, be started at a low dose at first (500 mg po bid)

\section{Alternative drugs if metformin is contraindicated or poorly tolerated Sulfonylureas/glinides}

Sulfonylurea treatment has been well established for decades but carries a risk of hypoglycemia, especially in elderly and multimorbid patients. In a populationbased study in Germany, Holstein et al. (39) documented the occurrence of 0.9 to 5.6 severe hypoglycemic episodes per 1000 patient-years, depending on the particular sulfonylurea drug that was used. Moreover, these drugs promote weight gain (31). Observational studies have also yielded some (not yet conclusive) evidence that sulfonylureas are associated with a higher cardiovascular risk than metformin (40, e1-e4). These drugs also seem to lose efficacy more rapidly than metformin (e5). Repaglinide, which has a similar side-effect profile to that of the sulfonylureas with a shorter duration of action, can also be used in patients with advanced renal insufficiency.

\section{Sulfonylureas}

Sulfonylurea treatment has been well established for decades but carries a risk of hypoglycemia, especially in elderly and multimorbid patients. 


\section{DPP-4 inhibitors and GLP1 receptor agonists}

Dipeptidylpeptidase-4 (DPP-4) inhibitors ("gliptins" such as vildagliptin, sitagliptin, saxagliptin, linagliptin, and alogliptin) inhibit the degradation of the incretin hormone glucagon-like peptide 1 (GLP-1) and thereby increase its concentration.

Large-scale cardiovascular trials of saxagliptin and alogliptin for patients with a history of cardiovascular events were recently published (17 000 and 5000 patients, respectively) (e6, e7). Neither trial revealed an elevated risk of myocardial infarction, stroke, or other negative events, including pancreatitis and cancer. Unexpectedly, saxagliptin (but not alogliptin) was found to be associated with an elevated risk of hospitalization for heart failure. This finding requires further analysis.

The effect of GLP-1 is to stimulate insulin secretion and inhibit glucagon secretion in a manner that depends on the glucose concentration, resulting in hormone levels that are appropriate to momentary needs. It follows that the DPP-4 inhibitors have broad therapeutic applicability and carry a low risk of hypoglycemia when given as monotherapy or in combination with other drugs that do not cause hypoglycemia $(1$, e9). DPP-4 inhibitors have not been found to cause weight gain; they do have gastrointestinal side effects, however, and may cause urticaria (e9). Among the currently available DPP-4 inhibitors, sitagliptin, vildagliptin, saxagliptin, and linagliptin have been approved for use as monotherapy in patients for whom metformin is contraindicated or poorly tolerated. Linagliptin is not renally eliminated and can be given to patients with renal insufficiency without dose adjustment. In contrast, the doses of sitagliptin, vildagliptin, and saxagliptin do need to be adjusted for renal insufficiency. The GLP-1 receptor agonists exenatide, liraglutide, and lixisenatide are not currently approved for monotherapy.

\section{Acarbose}

Acarbose inhibits intestinal alpha-glucosidases, lowers the insulin requirement without causing hypoglycemia, and causes neither weight loss nor weight gain (e8, e9). Gastrointestinal side effects are common (e8).

\section{Pioglitazone}

Pioglitazone is the only glitazone approved for clinical use. Its advantages are a very low risk of hypoglycemia in monotherapy and the fact that it can be taken by patients with advanced renal insufficiency. Its disadvantages are weight gain, fluid retention that can worsen cardiac insufficiency (contraindicated for patients with NYHA class I-IV cardiac insufficiency), an increased risk of bone fractures, and, possibly, an increased incidence of bladder cancer (e5, e11). In July 2011, the European Medicines Agency decided that, despite these disadvantages, pioglitazone is still a valid therapeutic option for some patients. In the reimbursement scheme of the German statutory health insurance system, pioglitazone may only be used when explicitly justified in certain special situations, e.g., special cases of renal insufficiency or occupational situations that make it vitally important to eliminate the risk of hypoglycemia entirely when this cannot be achieved with other drugs, as when the patient operates a passenger-carrying vehicle.

\section{SGLT-2 inhibitors}

SGLT-2 inhibitors lessen renal glucose resorption and thus cause glycosuria and a resulting insulinindependent reduction in the blood glucose concentration, as well as $2-4 \mathrm{~kg}$ of weight loss. SGLT-2 inhibitors do not confer any risk of hypoglycemia when used in combination with metformin. Their use is associated with an increased incidence of genital infections. The osmotic diuresis that they cause leads to a mild drop in blood pressure, which may be additive in combination with the effect of other diuretics that the patient may be taking. SGLT-2 inhibitors are less effective when the GFR is less than $60 \mathrm{~mL} / \mathrm{min}$. Endpoint trials are not yet available.

\section{Overview of therapeutic options}

In summary, many different treatments are available for lowering the blood glucose concentration. All of the pertinent guidelines, as well as the German National Disease Management Guideline on the Treatment of Type 2 Diabetes (based on a broad consensus in consideration of all currently available evidence), contain the recommendation that metformin should be the first drug given when drug therapy is begun (Figure). For patients with a contraindication to metformin treatment, or those who tolerate the drug poorly, it is more difficult to state which alternative treatment is best on the basis of good endpoint data; the recommendations of the Akd ̈̈ and DEGAM for such patients differ somewhat from those of the

\section{Glomerular filtration rate}

Metformin is contraindicated if GFR $<60 \mathrm{~mL} / \mathrm{min}$, sulfonylureas if GFR $<30 \mathrm{~mL} / \mathrm{min}$.

\section{Antidiabetic drugs in renal insufficiency}

Whatever the GFR may be, patients who cannot achieve an adequate metabolic state or have hypoglycemic episodes under treatment with oral antidiabetic drugs should be started on insulin. 
DDG and DGIM. The AkdÄ and DEGAM recommendations proceed from the fact that endpoint trials have revealed a benefit only for human insulin and glibenclamide (glyburide). DPP-4 inhibitors, glucosidase inhibitors, and sulfonylureas other than glibenclamide are listed as alternatives to metformin, but with the remark that their benefit has not been documented in endpoint trials. In contrast, the DDG and DGIM recommendations contain a list of all currently available therapeutic options without any further evaluation, based on the reasoning that all drugs have advantages and disadvantages, and that these must always be discussed with the patient on an individual basis, with particular attention to multimorbidity and to the patient's preferences.

Furthermore, the DDG and DGIM do not hold the evidence that glibenclamide improves clinical endpoints to be entirely convincing; on the contrary, they infer from a number of retrospective analyses that this drug may actually significantly increase the risk of cardiovascular complications and death. They point out that glibenclamide treatment is associated with a risk of hypoglycemia, and with weight gain. Although the other antidiabetic drugs listed as alternatives to metformin have not yet been shown to improve clinical endpoints, they are known to have much more favorable risk profiles than the sulfonylureas.

In our view, decisions about antidiabetic drugs should be made individually for each patient, on the basis of the particular clinical situation and in mutual agreement with the patient. If the risk of hypoglycemia must be eliminated as thoroughly as possible (e.g., for patients who operate passenger-carrying vehicles), if there are other factors that make the risk of hypoglycemia more likely, or if the patient is markedly obese, then the use of sulfonylureas or insulin may well be problematic (19). Insulin, DPP-4 inhibitors, repaglinide, and pioglitazone can be used in patients with advanced renal insufficiency (Table).

\section{Treatment escalation if monotherapy fails}

If metformin monotherapy results in an $\mathrm{HbA} 1 \mathrm{c}$ value that is still elevated beyond the agreed-upon target range (generally between $6.5 \%$ and $7.5 \%$ ), then the treatment can be amplified with the addition of a second antidiabetic drug (combination therapy), or else metformin can be discontinued and insulin used alone (Figure). Once again, there are differing recommendations about treatment escalation from the AkdÄ and DEGAM on the one hand and from the DDG and DGIM on the other. The former two societies name three possible alternatives and state that the advantages and disadvantages of each should be considered individually in each case. The latter two societies state that, in principle, once the advantages and risks have been considered (with the patient participating in the discussion), all of the other drugs listed in the Table are valid options for combination therapy (Figure) $(1,19,31)$.

The combination of a sulfonylurea or repaglinide with metformin has a clear antihyperglycemic effect. Its disadvantages include the risk of hypoglycemia and the danger of weight gain and, possibly, cardiovascular side effects $(19$, e4). The DPP-4 inhibitors have a broader therapeutic application and a low risk of causing hypoglycemia when they are given as monotherapy or in combination with other drugs that only rarely cause hypoglycemia $(1, \mathrm{e} 9)$.

Injectable GLP-1 receptor agonists (Table) have also been approved for use in combination with metformin. Their GLP-1-like effect is stronger and longer lasting than that of the DPP-4 inhibitors (e12); aside from lowering the blood glucose level and the HbAlc fraction, the GLP-1-like effect also slows gastric emptying and stimulates the hypothalamic satiety center. Thus, GLP-1 receptor agonists tend to cause weight loss, particularly when compared to insulin or sulfonylureas (e13, e14). Their most common side effects are nausea and a feeling of fullness (e12). These tend to arise during the first few weeks of treatment and can be avoided by titrating the dose slowly upward. The currently approved GLP-1 receptor agonists-exenatide, lixisenatide, and liraglutide-must be injected subcutaneously once or twice daily. Exenatide has also been available since June 2011 in an extendedrelease preparation that only needs to be injected once a week (e15, e16). It is not yet entirely clear whether GLP-1 receptor agonists increase the risk of pancreatitis (e16, e17). Because a small number of cases of pancreatitis during treatment with GLP-1 analogues have been reported, the physician information leaflets contain recommendations that the patient should be informed about the symptoms of pancreatitis to watch for, that the drug should be discontinued if pancreatitis is suspected, and that it should not be used if the patient is known to have pancreatitis. A combination of metformin with a

\section{Treatment escalation if monotherapy fails}

If monotherapy yields an $\mathrm{HbA1c}$ value higher than the target range, then the treatment should be amplified with the addition of a second antidiabetic drug.

\section{Combinations to be determined individually}

The add-on drug in combination therapy must be determined individually for each patient. 
GLP-1 receptor agonist is highly effective, confers only a low risk of hypoglycemia, and can help the patient lose weight; it is therefore especially advantageous for obese patients, for those who are prone to hypoglycemia, and for those who, for occupational reasons, must keep their risk of hypoglycemic episodes to a minimum (e14-e17). Endpoint trials have yet to be performed. If metformin is contraindicated, a GLP-1 receptor agonist can be combined with a sulfonylurea (e18). Hypoglycemia may arise with this combination.

\section{Treatment escalation if dual therapy fails}

It is unclear whether a triple combination is better or worse, with respect to pertinent clinical endpoints, than insulin therapy combined with (at most) one other antidiabetic drug (31, e19-e22). The new German National Disease Management Guideline on the Treatment of Type 2 Diabetes contains a recommendation for switching to combination therapy with insulin (Figure), because insufficient data are available regarding triple combinations (19). Aside from special situations, such as that of a bus driver or pilot who can keep working as usual under combination therapy with (e.g.) metformin, a DPP-4 inhibitor, and pioglitazone without any risk of hypoglycemia, many patients want to defer insulin treatment for as long as possible, and this may be a reason to begin triple combination therapy. The many potential combinations are discussed in the EASD/ADA position paper; close monitoring is recommended (1).

\section{Antihyperglycemic drugs in combination with insulin}

Basal insulin is often given in combination with an oral antidiabetic drug; the DDG discussed this type of combination in its proposal for a national disease management guideline (19). As long as metformin is not contraindicated or poorly tolerated, metformin can continue to be given when insulin therapy is begun, and over the further course of insulin therapy as well (Figure). This lowers overall insulin consumption and also causes less weight gain than insulin treatment alone. It remains unclear whether any additional benefit can be gained from supplementing basal insulin therapy (with or without metformin) with another drug to increase postprandial insulin secretion, e.g., a sulfonylurea, DPP-4 inhibitor, or GLP-1 receptor agonist (31).

\section{Treatment escalation if dual therapy fails}

It is unclear whether a triple combination is better or worse than insulin therapy combined with (at most) one other antidiabetic drug, if treatment with two oral antidiabetic drugs fails.

\section{Strategies for insulin therapy}

The goals of insulin therapy in type 2 diabetes are glycemic and metabolic control to prevent microand macrovascular complications, while avoiding the hypoglycemic episodes and marked weight gain that may arise if the insulin dose is too high or incorrectly distributed. In conventional therapy (CT), a mixed insulin injection is generally given twice daily; intensified conventional therapy (ICT) involves basal insulin administration and insulin boluses with each meal; a third alternative - continuous, subcutaneous insulin infusion (CSII, i.e., insulin pump therapy) - is not recommended for patients with type 2 diabetes. There is as yet no evidence from clinical trials on the advantages and disadvantages of each of these types of insulin therapy with respect to "hard" endpoints. ICT is recommended whenever feasible, as some evidence suggests it may be superior to CT (16) (Figure). The use of a particular treatment regimen should be based on the patient's individual needs, quality of life, and metabolic state and should be explicitly agreed upon with the patient $(1,19,27)$.

Patients with type 2 diabetes usually have some degree of residual insulin secretion when they start insulin therapy. An ICT regimen may thus be unnecessary at first, and therapy can begin either with basal injections or with injections at mealtimes, rather than both. There are arguments for each alternative. For example, basal insulin treatment would seem appropriate for patients whose fasting blood glucose concentration is high in the morning (above the target range of $80-120 \mathrm{mg} / \mathrm{dL}$ ); it can be lowered by the administration of a long-acting insulin preparation in the evening to suppress hepatic glucose production (1). The treatment begins at a dose of 10 to 20 IU of a long-acting insulin preparation, depending on the patient's weight, with a dose increase by 2 IU every three days until the morning glucose values are in the target range. Nocturnal hypoglycemia, which typically arises between 2 a.m. and 5 a.m. without being noticed, may be a problem. In the initial dose-adjustment phase, the nocturnal blood glucose concentration should be checked as well. Nocturnal hypoglycemia is less common when long-acting insulin analogues are used (e23).

On the other hand, if glycemic peaks after meals are the main problem, then insulin therapy would more reasonably be initiated with insulin adminis-

\section{Strategies for insulin therapy}

The use of a particular treatment regimen should be based on the patient's individual needs, quality of life, and metabolic state and should be explicitly agreed upon with the patient. 
tration only at mealtimes. Fixed doses can be given at mealtimes if the patient regularly takes meals of unvarying size; otherwise, the dose can be adapted to meals and blood glucose values $(1$, e24). Both the DDG guidelines (28) and the EASD/ADA recommendations stress that there is only weak evidence for this approach, and that numerous individual aspects must be taken into consideration (1, e24).

Many different titration schemes have been published. For a highly motivated patient who cannot be adequately treated in any simpler way, one might proceed as follows: The required dose depends on the patient's sensitivity to insulin. 1-2 IU of insulin are needed per $40 \mathrm{kcal}$ of carbohydrate if the patient's insulin sensitivity is normal (40 kcal corresponds to one carbohydrate unit, or to 10-12 g of carbohydrate). Insulin-resistant type 2 diabetics may need several times this dose. The insulin requirement is empirically determined, and a scheme is created in which the patient is given a dose of insulin calculated from the amount of carbohydrate ingested. The patient should measure his or her own blood glucose concentration and inject corrective doses depending on the current value. Insulin-sensitive patients are assumed to need 1 IU of insulin per $30-40 \mathrm{mg} / \mathrm{dL}(1.7-2.2 \mathrm{mmol} / \mathrm{L})$ elevation of blood glucose concentration; insulinresistant patients need much higher corrective doses. All patients should learn the rules of insulin treatment in special training sessions. They must also be taught the proper course of action in case of a hypoglycemic episode, the effects of physical activity, and the other factors that can influence the efficacy of insulin treatment (28).

\section{Conflict of interest statement \\ Prof. Pfeiffer has received consulting fees from Novo, Berlin Chemie, Novartis, Astra Zeneca/BMS, Sanofi, Lilly, and Boehringer-Ingelheim and reimbursement of conference participation fees from $A$ \& A and Boehringe Ingelheim. He has received payment for preparing continuing medical edu- cation presentations from Lilly, Thieme, PriMed, Novo, Berlin Chemie, MSD, and Sanofi. He has received payment to a third-party-funding account for performing clinical trials on behalf of Roche, Takeda, Astra Zeneca, and Novo. He has received financial support from Novartis, Bayer and Rettenmayer \& Söhne for a research project that he initiated. \\ Prof. Klein has received consulting fees from GlaxoSmithKline, Sanofi- Aventis, Janssen-Cilag, and AstraZeneca and reimbursement of confer- ence participation fees from Lilly, Novartis, and AstraZeneca. He has re- ceived payment for preparing continuing medical education presentations from Novo Nordisk. He has received financial support from GlaxoSmith- Kline and Sanofi Aventis for a research project that he initiated.}

Manuscript received on 29 September 2011; revised version accepted on 3 November 2013.

Translated from the original German by Ethan Taub, M.D.

\section{REFERENCES}

1. Inzucchi SE, Bergenstal RM, Buse JB, et al.: Management of hyperglycaemia in type 2 diabetes: a patient-centered approach. Position statement of the American Diabetes Association (ADA) and the European Association for the Study of Diabetes (EASD). Diabetologia 2012; 55: 1577-96.

2. DeFronzo RA: Insulin resistance, lipotoxicity, type 2 diabetes and atherosclerosis: the missing links. The Claude Bernard Lecture 2009. Diabetologia 2010; 53: 1270-87.
3. Paulweber B, Valensi P, Lindstrom J, et al.: A European evidence-based guideline for the prevention of type 2 diabetes. Horm Metab Res 2010; 42 (Suppl 1): 3-36.

4. Imamura M, Maeda S. Genetics of type 2 diabetes: the GWAS era and future perspectives. Endocr J 2011; 58: 723-39.

5. Europe I: The International Diabetes Federation. Diabetes Atlas. 2009; $4^{\text {th }}$ edition: www.idf.org/atlasmap/atlasmap (Last accessed on 13 Januaray 2014)

6. Seshasai SR, Kaptoge S, Thompson A, et al.: Diabetes mellitus, fasting glucose, and risk of cause-specific death. N Engl J Med 2011; 364: 829-841.

7. Kelley DE, Wing R, Buonocore C, Sturis J, Polonsky K, Fitzsimmons $M$ : Relative effects of calorie restriction and weight loss in noninsulin-dependent diabetes mellitus. J Clin Endocrinol Metab. 1993; 77: 1287-93.

8. Markovic TP, Jenkins AB, Campbell LV, Furler SM, Kraegen EW, Chisholm DJ: The determinants of glycemic responses to diet restriction and weight loss in obesity and NIDDM. Diabetes Care 1998; 21: 687-94

9. Intensive blood-glucose control with sulphonylureas or insulin compared with conventional treatment and risk of complications in patients with type 2 diabetes (UKPDS 33). UK Prospective Diabetes Study (UKPDS) Group. Lancet 1998; 352: 837-53.

10. Wing RR, Lang W, Wadden TA, et al.: Benefits of Modest Weight Loss in Improving Cardiovascular Risk Factors in Overweight and Obese Individuals With Type 2 Diabetes. Diabetes Care 2011; 34: 1481-6.

11. Wing RR: Long-term effects of a lifestyle intervention on weight and cardiovascular risk factors in individuals with type 2 diabetes mellitus: four-year results of the Look AHEAD trial. Arch Intern Med 2010; 170: 1566-75.

12. Lim EL, Hollingsworth KG, Aribisala BS, Chen MJ, Mathers JC, Taylor R: Reversal of type 2 diabetes: normalisation of beta cell function in association with decreased pancreas and liver triacylglycerol. Diabetologia 2011; 54: 2506-14.

13. Selvin E, Steffes MW, Zhu H, et al.: Glycated hemoglobin, diabetes, and cardiovascular risk in nondiabetic adults. $\mathrm{N}$ Engl J Med 2010; 362: 800-811.

14. Summary of revisions for the 2010 Clinical Practice Recommendations. Diabetes Care 2010; 33 (Suppl 1): 3.

15. Kerner W, Brückel J: Definition, Klassifikation und Diagnostik des Diabetes mellitus. Diabetologie 2011; Suppl 2: 107-10.

16. Ohkubo Y, Kishikawa $H$, Araki $E$, et al.: Intensive insulin therapy prevents the progression of diabetic microvascular complications in Japanese patients with non-insulin-dependent diabetes mellitus: a randomized prospective 6-year study. Diabetes Res Clin Pract 1995; 28(2): 103-17.

17. UK Prospective Diabetes Study (UKPDS): X. Urinary albumin excretion over 3 years in diet-treated type 2, (non-insulindependent) diabetic patients, and association with hypertension, hyperglycaemia and hypertriglyceridaemia. Diabetologia 1993; 36: 1021-9.

18. Patel A, MacMahon S, Chalmers J, et al.: Intensive blood glucose control and vascular outcomes in patients with type 2 diabetes. N Engl J Med 2008; 358: 2560-72.

19. Giani G, Janka HU, Hauner H, et al.: Epidemiologie und Verlauf des Diabetes mellitus in Deutschland. Evidenzbasierte Leitlinie DDG - Aktualisierung 05/2004. www.deutsche-diabetes-gesells chaft.de/fileadmin/Redakteur/Leitlinien/Evidenzbasierte_Leitlinien/EBL_Epidemiologie_Update_2004.pdf (last accessed on 9 October 2013).

20. Gerstein HC, Miller ME, Genuth S, et al.: Long-term effects of intensive glucose lowering on cardiovascular outcomes. N Engl J Med 2011; 364: 818-28.

21. Duckworth W, Abraira C, Moritz T, et al.: Glucose control and vascular complications in veterans with type 2 diabetes. $\mathrm{N}$ Engl J Med 2009; 360: 129-39. 
22. Ray KK, Seshasai SR, Wijesuriya S, et al.: Effect of intensive control of glucose on cardiovascular outcomes and death in patients with diabetes mellitus: a meta-analysis of randomised controlled trials. Lancet 2009; 373: 1765-72.

23. Hemmingsen B, Lund SS, Gluud C, et al.: Intensive glycaemic control for patients with type 2 diabetes: systematic review with meta-analysis and trial sequential analysis of randomised clinical trials. BMJ 2011; 343: d6898

24. IQWiG. Nutzenbewertung einer langfristigen normnahen Blutzuckersenkung bei Patienten mit Diabetes mellitus Typ 2. IQWiGBerichte - Jahr: 2011 Nr. 87 2011; www.iqwig.de/download/ A05-07 Rapid-Report Normnahe-Blutzuckersenkung-beiDiabetes- mellitus-Typ-2.pdf (last accessed on 16 September 2012).

25. Zannad F, Stough WG, Pocock SJ, et al.: Diabetes clinical trials: helped or hindered by the current shift in regulatory requirements? Eur Heart J 2012; 33: 1049-57.

26. Holman RR, Paul SK, Bethel MA, Matthews DR, Neil HA: 10-year follow-up of intensive glucose control in type 2 diabetes. N Engl J Med 2008; 359: 1577-89.

27. Bundesärztekammer (BÄK), Kassenärztliche Bundesvereinigung (KBV), Arbeitsgemeinschaft der Wissenschaftlichen Medizinischen Fachgesellschaften (AWMF): Nationale VersorgungsLeitlinie Therapie des Typ-2-Diabetes-Langfassung, 1st edition, Version 2. 2013 last updated on September 2013 Available from: www.versor gungsleitlinien.de/themen/diabetes2/dm2_Therapie (last accessed on 11. January 2014).

28. Matthaei S, Bierwirth R, Fritsche A, et al.: Medikamentöse antihyperglykämische Therapie des Diabetes mellitus Typ 2. Update der evidenzbasierten Leitlinie der Deutschen Diabetes-Gesellschaft. Exp Clin Endocrinol Diabetes 2009; 117: 522-57.

29. Sacks DB, Arnold M, Bakris GL, et al.: Guidelines and recommendations for laboratory analysis in the diagnosis and management of diabetes mellitus. Diabetes Care 2011; 34: e61-99.

30. American Diabetes Association: Standards of medical care in diabetes-2011. Diabetes Care 2011; 34 (Suppl 1): 11-61.

31. Gross JL, Kramer CK, Leitao CB, et al.: Effect of antihyperglycemic agents added to metformin and a sulfonylurea on glycemic control and weight gain in type 2 diabetes: a network meta-analysis. Ann Intern Med 2011; 154: 672-9.

32. UK Prospective Diabetes Study (UKPDS) Group: Effect of intensive blood-glucose control with metformin on complications in overweight patients with type 2 diabetes (UKPDS 34). Lancet 1998; 352: 854-65.
33. Monami M, Colombi C, Balzi D, et al.: Metformin and cancer occurrence in insulin-treated type 2 diabetic patients. Diabetes Care 2011; 34: 129-31.

34. Lee MS, Hsu CC, Wahlqvist ML, Tsai HN, Chang YH, Huang YC: Type 2 diabetes increases and metformin reduces total, colorec tal, liver and pancreatic cancer incidences in Taiwanese: a representative population prospective cohort study of 800000 individuals. BMC Cancer 2011; 11: 20

35. Shaw JS, Wilmot RL, Kilpatrick ES: Establishing pragmatic estimated GFR thresholds to guide metformin prescribing. Diabet Med 2007; 24: 1160-3.

36. Herrington WG, Levy JB: Metformin: effective and safe in renal disease? Int Urol Nephrol 2008; 40: 411-7.

37. Salpeter SR, Greyber E, Pasternak GA, Salpeter EE: Risk of fatal and nonfatal lactic acidosis with metformin use in type 2 diabetes mellitus. Cochrane Database Syst Rev 2010: CD002967.

38. Salpeter SR, Greyber E, Pasternak GA, Salpeter Posthumous EE: Risk of fatal and nonfatal lactic acidosis with metformin use in type 2 diabetes mellitus. Cochrane Database Syst Rev 2010: CD002967.

39. Holstein A, Plaschke A, Egberts EH: Lower incidence of severe hypoglycaemia in patients with type 2 diabetes treated with glimepiride versus glibenclamide. Diabetes Metab Res Rev 2001; 17: 467-73.

40. Murata GH, Duckworth WC, Hoffman RM, Wendel CS, Mohler MJ, Shah JH: Hypoglycemia in type 2 diabetes: a critical review. Biomed Pharmacother 2004; 58: 551-9.

\section{Corresponding author}

Prof. Dr. med. Andreas F. H. Pfeiffer

Deutsches Institut für Ernährungsforschung (DlfE) Potsdam-Rehbrücke

Abteilung für Klinische Ernährung

Arthur-Scheunert-Allee 114-116

14558 Nuthetal, Germany

afhp@dife.de

\section{Further information on GME}

This article has been certified by the North Rhine Academy for Postgraduate and Continuing Medical Education. Deutsches Ärzteblatt provides certified continuing medical education (CME) in accordance with the requirements of the Medical Associations of the German federal states (Länder). CME points of the Medical Associations can be acquired only through the Internet, not by mail or fax, by the use of the German version of the CME questionnaire. See the following website: cme.aerzteblatt.de.

Participants in the CME program can manage their CME points with their 15-digit "uniform CME number" (einheitliche Fortbildungsnummer, EFN). The EFN must be entered in the appropriate field in the cme.aerzteblatt.de website under "meine Daten" ("my data"), or upon registration. The EFN appears on each participant's CME certificate.

The present CME unit can be accessed until 27 April 2014. The CME unit "The Febrile Child: Diagnosis and Treatment" (Issue 45/2013) can be accessed until 9 February 2014, the CME unit "The Diagnosis and Treatment of Celiac Disease" (Issue 49/2013) until 9 March 2014, and the CME unit "Rhegmatogenous Retinal Detachment-an Ophthalmologic Emergency" (Issue 1-2/2014) until 30 March 2014.

For Issue 9/2014, we plan to offer the topic "Acute otitis media: a structured approach." 
Please answer the following questions to participate in our certified Continuing Medical Education program. Only one answer is possible per question. Please select the answer that is most appropriate.

Question 1

Which of the following antidiabetic drugs or drug classes is most likely to cause hypoglycemia?

a) metformin, b) DPP-4 inhibitors, c) sulfonylureas, d) pioglitazone, e) acarbose

\section{Question 2}

According to the German National Disease Management Guideline on the Treatment of Type 2 Diabetes, what is the first step of basal therapy for patients with type 2 diabetes?

a) behavioral therapy, Alexander technique, vegan nutrition, memory training

b) fasting, fitness training, psychoanalysis, breathing training

c) patient education, dietary counseling, exercise, smoking cessation

d) talk therapy, protein restriction, bed rest, meditation

e) psychoanalysis, attentiveness training, rest, carbohydrate restriction

Question 3

Under treatment with metformin, your patient did not reach a satisfactory HbA1c level and gained weight. Which of the following addon drugs or drug regimens would be least likely to cause additional weight gain when given in combination with metformin?

a) a long-acting insulin preparation given in the morning

b) a GLP-1 receptor agonist

c) a sulfonylurea

d) a glinide

e) intensified insulin therapy

Question 4

For the treatment of hyperglycemia in the setting of severe renal insufficiency (GFR $15-30 \mathrm{~mL} / \mathrm{min}$ ), when there remains some degree of residual insulin secretion: [complete the sentence]

a) insulin is the only approved form of treatment.

b) GLP-1 agonists (exenatide and liraglutide) can be considered as possible alternatives, but their dose may need to be adjusted (according to the physician information leaflet).

c) DPP-4 inhibitors and repaglinide can be considered as possible alternatives, but their dose may need to be adjusted (according to the physician information leaflet).

d) sulfonylureas (glibenclamide, glimepiride) can be considered as possible alternatives, but their dose may need to be adjusted (according to the physician information leaflet).

e) metformin can be given in a reduced dose (500 mg po bid) (according to the physician information leaflet).

Question 5

Which of the following antidiabetic drugs or drug classes is contraindicated when the glomerular filtration rate is lower than $\mathbf{6 0}$ $\mathrm{mL} / \mathrm{min}$ and, according to the physician information leaflet, should not be given in an adapted dose either?

a) pioglitazone, b) glinides, c) DPP-4 inhibitors, d) metformin, e) insulin

\section{Question 6}

What is an important consideration when metformin is given for antihyperglycemic treatment?

a) Patients with a body-mass index (BMI) above $30 \mathrm{~kg} / \mathrm{m}^{2}$ have a higher risk of lactic acidosis because of the mobilization of free fatty acids from adipocytes.

b) Although the effect on blood sugar is beneficial, clinical studies definitively show an increased risk of cancer.

c) Metformin is contraindicated for patients with NYHA I heart failure.

d) Metformin should not be given in combination with DPP-4 inhibitors.

e) Gastrointestinal side effects are common.
Question 7

Your patient, a male bus driver, age 55 (BMI $29 \mathrm{~kg} / \mathrm{m}^{2}$ ), has had well-controlled diabetes for 5 years under treatment with metformin $850 \mathrm{mg}$ po bid. Now, however, despite adherence to basal treatment (nutrition, exercise), his HbA1c has risen to $7.9 \%$ (62.8 $\mathrm{mmol} / \mathrm{mol}$ ). What is your best course of action?

a) Continue the treatment unchanged and accept the low risk of longterm complications to spare the patient difficulties at work.

b) Start insulin treatment, which is clearly indicated by the high $\mathrm{HbA1c}$

c) Give pioglitazone as an add-on drug, because this is now the only drug that can be given together with metformin with a low risk of hypoglycemia.

d) Tell the patient a number of other drugs can be given together with metformin to lower the blood sugar without any appreciable risk of hypoglycemia; although scientific proof is not yet available, it seems that such a combination probably prevents long-term complications.

e) After extensive patient education and training, start insulin-pump therapy. As the pump spreads out the insulin dose evenly over time, there is no relevant risk of hypoglycemia for this bus-driving patient

\section{Question 8}

A man with longstanding type 2 diabetes, BMI $31.5 \mathrm{~kg} / \mathrm{m}^{2}$, and two prior myocardial infarctions (1 and 2 years ago) is being treated with a sulfonylurea (glibenclamide) and an intensified insulin treatment scheme with a total of $60 \mathrm{IU}$ of insulin per day. His $\mathrm{HbA1c}$ value is $9 \%(75 \mathrm{mmol} / \mathrm{mol})$, and his creatinine value is stable at ca. $2 \mathrm{mg} / \mathrm{dL}$ (177 $\mu \mathrm{mol} / \mathrm{L})$. He reports that his blood sugar fluctuates widely, and that he has had two severe hypoglycemic episodes in the past year. What should be done?

a) The sulfonylurea drug should still be given, because such drugs have a beneficial effect on nutrition-dependent insulin secretion.

b) The sulfonylurea drug should be discontinued and replaced with metformin so that the patient will need less insulin.

c) The sulfonylurea drug should be stopped and the insulin therapy should be optimized for an $\mathrm{HbA} 1 \mathrm{c}$ target below $6.5 \%$ (48 $\mathrm{mmol} / \mathrm{mol})$, even though this may cause more freuqent hypoglycemic episodes.

d) Insulin should be given alone, with an $\mathrm{HbA1c}$ target that can be achieved without risk of causing hypoglycemia.

e) To prevent hypoglycemic episodes, insulin should be stopped and a DPP-4 inhibitor should be given instead.

\section{Question 9}

For what type of patient would it make the most sense to set the $\mathrm{HbA1c}$ target at $6.5 \%(48 \mathrm{mmol} / \mathrm{mol})$ or even lower?

a) a patient who has been taking insulin for many years and has had multiple myocardial infarctions

b) an elderly patient

c) a patient with a high insulin requirement

d) a patient in whom type 2 diabetes was recently diagnosed and can be easily controlled with lifestyle changes and metformin

e) a patient whose diabetes is hard to control

Question 10

What type of antihyperglycemic therapy is most likely to cause weight gain?

a) exercise

b) metformin

c) sulfonylureas

d) GLP-1 receptor agonists

e) DPP-4 inhibitors 


\title{
CONTINUING MEDICAL EDUCATION
}

\section{The Treatment of Type 2 Diabetes}

\author{
Andreas F. H. Pfeiffer, Harald H. Klein
}

\section{EREFERENCES}

e1. Currie CJ, Peters JR, Tynan A, et al.: Survival as a function of $\mathrm{HbA}(1 \mathrm{c})$ in people with type 2 diabetes: a retrospective cohort study. Lancet 2010; 375: 481-9.

e2. Tzoulaki I, Molokhia M, Curcin V, et al.: Risk of cardiovascular disease and all cause mortality among patients with type 2 diabetes prescribed oral antidiabetes drugs: retrospective cohort study using UK general practice research database. BMJ 2009; 339:b 4731

e3. Schramm TK, Gislason GH, Vaag A, et al.: Mortality and cardiovascular risk associated with different insulin secretagogues compared with metformin in type 2 diabetes, with or without a previous myocardial infarction: a nationwide study. Eur Heart $\mathrm{J}$ 2011; 32: 1900-8.

e4. Rao AD, Kuhadiya N, Reynolds K, Fonseca VA: Is the combination of sulfonylureas and metformin associated with an increased risk of cardiovascular disease or all-cause mortality? a meta-analysis of observational studies. Diabetes Care 2008; 31:1672-8.

e5. Kahn SE, Haffner SM, Heise MA, et al.: Glycemic durability of rosiglitazone, metformin, or glyburide monotherapy. N Engl J Med 2006; 355: 2427-43.

e6. White WB, Cannon CP, Heller SR, et al.: Alogliptin after acute coronary syndrome in patients with type 2 diabetes. N Engl J Med 2013; 369: 1327-35.

e7. Scirica BM, Bhatt DL, Braunwald E, et al.: Saxagliptin and cardiovascular outcomes in patients with type 2 diabetes mellitus. $N$ Engl J Med 2013; 369: 1317-26.

e8. van de Laar FA, Lucassen PL, Akkermans RP, van de Lisdonk EH, Rutten GE, van Weel C: Alpha-glucosidase inhibitors for patients with type 2 diabetes: results from a Cochrane systematic review and meta-analysis. Diabetes Care 2005; 28: 154-63.

e9. Karagiannis T, Paschos P, Paletas K, Matthews DR, Tsapas A: Dipeptidyl peptidase- 4 inhibitors for treatment of type 2 diabetes mellitus in the clinical setting: systematic review and metaanalysis. BMJ 2012; 344: 1369.

e10. Campbell RK, Cobble ME, Reid TS, Shomali ME: Distinguishing among incretin-based therapies. Pathophysiology of type 2 diabetes mellitus: potential role of incretin-based therapies. $J$ Fam Pract 2010; 59: 5-9.

e11. Bennett WL, Maruthur NM, Singh S, et al.: Comparative effectiveness and safety of medications for type 2 diabetes: an update including new drugs and 2-drug combinations. Ann Intern Med 2011; 154: 602-13.

e12. Drucker DJ, Nauck MA: The incretin system: glucagon-like peptide-1 receptor agonists and dipeptidyl peptidase- 4 inhibitors in type 2 diabetes. Lancet 2006; 368: 1696-1705.

e13. Liu SC, Tu YK, Chien MN, Chien KL: Effect of antidiabetic agents added to metformin on glycaemic control, hypoglycaemia and weight change in patients with type 2 diabetes: a network metaanalysis. Diabetes Obes Metab 2012; 14: 810-20.

e14. Gallwitz B, Guzman J, Dotta F, et al.: Exenatide twice daily versus glimepiride for prevention of glycaemic deterioration in patients with type 2 diabetes with metformin failure (EUREXA): an openlabel, randomised controlled trial. Lancet 2012; 379: 2270-8. e15. Diamant M, Van Gaal L, Stranks S, et al.: Safety and efficacy of once-weekly exenatide compared with insulin glargine titrated to target in patients with type 2 diabetes over 84 weeks. Diabetes Care 2012; 35: 683-9.

e16. Drucker DJ, Sherman SI, Bergenstal RM, Buse JB: The safety of incretin-based therapies-review of the scientific evidence. J Clin Endocrinol Metab 2011; 96: 2027-31.

e17. Spranger J, Gundert-Remy U, Stammschulte T. GLP-1-based therapies: the dilemma of uncertainty. Gastroenterology 2011; 141 : 20-3.

e18. Hermansen K, Kipnes M, Luo E, Fanurik D, Khatami H, Stein P: Efficacy and safety of the dipeptidyl peptidase-4 inhibitor, sitagliptin, in patients with type 2 diabetes mellitus inadequately controlled on glimepiride alone or on glimepiride and metformin. Diabetes Obes Metab 2007; 9: 733-45.

e19. Vaag A, Lund SS: Insulin initiation in patients with type 2 diabetes mellitus: treatment guidelines, clinical evidence and patterns of use of basal vs premixed insulin analogues. Eur J Endocrinol 2012; 166: 159-170

e20. Kendall DM, Riddle MC, Rosenstock J, et al.: Effects of exenatide (exendin-4) on glycemic control over 30 weeks in patients with type 2 diabetes treated with metformin and a sulfonylurea. Diabetes Care 2005; 28: 1083-91.

e21. Zinman B, Gerich J, Buse JB, et al.: Efficacy and safety of the human glucagon-like peptide-1 analog liraglutide in combination with metformin and thiazolidinedione in patients with type 2 diabetes (LEAD-4 Met+TZD). Diabetes Care 2009; 32: 1224-30.

e22. Bell DS, Dharmalingam M, Kumar S, Sawakhande RB: Triple oral fixed-dose diabetes polypill versus insulin plus metformin efficacy demonstration study in the treatment of advanced type 2 diabetes (TrIED study-II). Diabetes Obes Metab 2011;13: 800-5.

e23. Pontiroli AE, Miele L, Morabito A: Metabolic control and risk of hypoglycaemia during the first year of intensive insulin treatment in type 2 diabetes: systematic review and meta-analysis. Diabetes Obes Metab 2012; 14: 433-46.

e24. Davidson MB, Raskin P, Tanenberg RJ, Vlainic A, Hollander P: A stepwise approach to insulin therapy in patients with type 2 diabetes mellitus and basal insulin treatment failure. Endocr Pract 2011; 17: 395-403.

e25. Mann JI, De Leeuw I, Hermansen K, et al.: Evidence-based nutritional approaches to the treatment and prevention of diabetes mellitus. Nutr Metab Cardiovasc Dis 2004;14: 373-94.

e26. Toeller M: Evidenzbasierte Ernährungsempfehlungen zur Behandlung und Prävention des Diabetes mellitus. Diabetes und Stoffwechsel 2005; 14: 75-94.

e27. Wadden TA, Neiberg RH, Wing RR, et al.: Four-Year weight losses in the look AHEAD study: Factors associated with long-term success. Obesity 2011; 19: 1987-98.

e28. Mancia G, Laurent S, Agabiti-Rosei E, et al.: Reappraisal of European guidelines on hypertension management: a European Society of Hypertension Task Force document. J Hypertens 2009; 27: 2121-58. 